\title{
O ESTRESSE E A ENFERMAGEM - A PERCEPÇÃO DAS AUXILIARES DE ENFERMAGEM DE UMA INSTITUIÇÃO PÚBLICA
}

\author{
Stress and Nursing - the Nursing's Auxiliaries \\ Perception of a Public Institution \\ El Estrés y la Enfermería - la Percepción de Auxiliares \\ de Enfermería de una Institución Publica
}

Thelma Spindola

Elizabeth Rose da Costa Martins

\begin{abstract}
Resumo
Estudo descritivo em abordagem qualitativa que teve como objetivo identificar como as auxiliares de enfermagem relacionam o estresse às suas atividades diárias. Foram investigadas 15 trabalhadoras de um hospital público no município do Rio de Janeiro. A análise temática dos resultados evidenciou que o estresse é percebido como um distúrbio emocional que acarreta desequilíbrio da saúde mental, ocasionando irritação, mau humor e incapacidade para o trabalho. Não se julgam estressadas, embora algumas refiram esta sensação em certas ocasiões. Acreditam que a atividade laboral pode contribuir para 0 estresse pelas condições e características do trabalho que realizam. Podemos concluir que embora definam o estresse como um distúrbio e atuem em condições desfavoráveis, nem todas percebem a influência destes fatores no seu equilíbrio emocional, sendo importante que se valorize a saúde mental dos trabalhadores, especialmente os profissionais de enfermagem, que necessitam estar bem física e mentalmente para interagirem com a clientela auxiliando-os.
\end{abstract}

Palavras-chave: Estresse. Saúde do Trabalhador. Ambulatório Hospitalar.

\section{Abstract}

This is a descriptive study, with a qualitative approach, which aimed at identifying how nursing auxiliaries relate stress to their daily activities. 15 Laborers women of a public hospital in Rio de Janeiro were investigated. The thematic analysis of the results revealed that stress is perceived as an emotional disorder which brings about mental health imbalance, causing irritation, bad humor and inability to work. These nurses do not consider themselves stressed, although some of them mention this sensation in certain occasions. They believe that their labor activity may contribute to stress, due to the conditions and characteristics of the work they do. We can conclude that although they define stress as a disorder and they work in unfavorable conditions, not all of them perceive the influence of these factors in their emotional balance, being important to give value to the workers' mental health, especially nursing professionals, who need to be physically and mentally well in order to interact with their clients, helping them.

Keywords:

Stress Occupational Health. Outpatients Clinics, Hospital.

\section{Resumen}

Estudio descriptivo, con abordaje cualitativo, que tuvo como objeto identificar como las auxiliares de enfermería relacionan el estrés a sus actividades diarias. Fueron investigadas 15 trabajadoras de un hospital público del municipio de Rio de Janeiro. El análisis temático de los resultados reveló que el estrés es percibido como un disturbio emocional que causa un desequilibrio en la salud mental, provocando irritación, mal humor, e incapacidad para el trabajo. Estas profesionales no se consideran estresadas, aunque algunas mencionen estas sensaciones en ciertas ocasiones. Ellas creen que la actividad laboral puede contribuir para el estrés, debido a las condiciones y características del trabajo que realizan. Podemos concluir aunque definan el estrés como un disturbio y actúen en condiciones desfavorables, no son todas las que perciben la influencia de estos factores en su equilibrio emocional, siendo importante que se valore la salud mental de los trabajadores, especialmente los profesionales de enfermería, que necesitan estar bien física y mentalmente para interactuar con sus clientes, ayudándolos.

Palabras clave:

Estrés. Salud Laboral. Servicio Ambulatorio en Hospital. 


\section{INTRODUÇÃO}

0 estresse é um distúrbio dos tempos atuais. Cada vez mais pessoas convivem com esta problemática nos grandes centros, envolvidas em suas trajetórias de vida e na organização social em que estão inseridas. 0 elevado número de pessoas que se concentram nas metrópoles, a busca incessante por melhores condições de vida (nem sempre tão satisfatórias), o mercado de trabalho, cada vez mais exigente, fazendo com que os trabalhadores mantenham-se em constante tensão para atender suas solicitações, a violência urbana que transforma a vida dos cidadãos tornando-os prisioneiros em seus próprios lares; enfim, inúmeras são as situações que atualmente perpassam o cotidiano da população nas metrópoles brasileira, transformando sua realidade.

0 estresse é uma reação do organismo causada por alterações psicofisiológicas que ocorrem quando a pessoa se depara com situações que interferem no seu equilíbrio interno ${ }^{1}$. 0 homem, como um ser produtivo passa em geral, a maior parte de sua vida no ambiente de trabalho.

Em nossa sociedade, o trabalho representa para o homem uma fonte de satisfação psíquica profunda. 0 trabalho de enfermagem é constituído por atividades relativas ao cuidado e administração do espaço assistencial, tendo como princípio a divisão parcelar ou pormenorizada do trabalho. As singularidades das ações da enfermagem são marcantes não somente por caracterizar-se como profissão essencialmente integrada por mulheres, mas também pela especificidade das atividades que desenvolvem no dia-a-dia.

Os enfermeiros e demais integrantes da equipe de enfermagem, freqüentemente no seu cotidiano, confrontamse com situações geradoras de estresse, seja pela urgência do atendimento ou pela escassez de recursos na prestação da assistência. Um estudo ${ }^{2}$ que avaliou as condições de trabalho dos profissionais de enfermagem de um hospital psiquiátrico constatou que os trabalhadores são submetidos a uma série de tensões que geram constantes falhas no processo de produção, reduzem a motivação no desempenho das tarefas e interferem nas relações interpessoais ${ }^{2}$.

Pesquisadores analisando a atividade ocupacional dos enfermeiros e suas relações com o estresse verificaram que 0 foco de maior atenção na ocupação desses profissionais aparece como fonte de estresse, ou seja, o paciente para o enfermeiro assistencial, o aluno para o enfermeiro docente e a assistência como um todo para o enfermeiro administrativo ${ }^{3}$.

As condições psicológicas do trabalho e suas conseqüências sobre a saúde do trabalhador foram investigadas, e foi observado que a organização do trabalho é um fator potencialmente desestabilizador da saúde mental dos trabalhadores ${ }^{4}$. Assim, "as pressões ligadas às condiç̃es de trabalho têm por alvo principal o corpo dos trabalhadores, onde elas podem ocasionar desgaste, envelhecimento e doenças somáticas" 4:125.

Os agentes estressores que agem nos trabalhadores podem ser oriundos do meio ambiente, do local de trabalho, ou estarem ligados a assuntos pessoais². Entende-se por ambiente laboral como "um conjunto de condições de vida dos trabalhadores no local de trabalho, englobando tanto as próprias características do próprio lugar quanto os elementos relacionados à atividade em si”2: 556 .

Neste sentido, o estresse ocupacional tem sido estudado porque interfere diretamente na vida dos trabalhadores, alterando os níveis de satisfação, produtividade e saúde das pessoas, ocasionando dificuldades de atenção e concentração, confusão mental, perda temporária da memória, irritabilidade, cansaço, mal-estar generalizado e acidentes ${ }^{5}$.

Atuando no ambulatório do Hospital Universitário Gaffrée e Guinle (HUGG) da Universidade Federal do Estado do Rio de Janeiro (UNIRIO), situado no município do Rio de Janeiro, e convivendo com dificuldades relativas ao tipo de trabalho desenvolvido, temos observado o aumento gradativo de queixas de cansaço, desgaste físico e emocional entre os profissionais que ali atuam, especialmente entre os integrantes da equipe de enfermagem. Outro aspecto que despertou nosso interesse foi o crescimento de afastamentos dos auxiliares de enfermagem decorrentes de patologias associadas ao esgotamento físico e mental, como hipertensão arterial, cardiopatia isquêmica e outras.

Conscientes de que o estresse pode contribuir para a etiologia de várias doenças mais graves e afetar profundamente a qualidade de vida das pessoas ${ }^{1}$, surgiu a motivação para a elaboração deste estudo com o objetivo de identificar como as auxiliares de enfermagem relacionam o estresse às suas atividades diárias.

\section{METODOLOGIA}

Trata de um estudo exploratório, descritivo em abordagem qualitativa, em que, em função do objeto de estudo selecionado "a visão das auxiliares de enfermagem acerca do estresse", a descrição da realidade do ambulatório hospitalar pelas trabalhadoras tornouse imprescindível para a compreensão deste cenário.

0 campo da pesquisa foi o ambulatório do HUGG da UNIRIO, situado no município do Rio de Janeiro. Este Hospital é uma instituição pública e federal que atende clientes oriundos do Rio de Janeiro (região metropolitana e demais municípios) e de outras cidades do Estado do Rio de Janeiro. 0 serviço de ambulatório tem uma demanda média de 500 atendimentos diários nas diversas especialidades, dentre elas: clínica médica, clínica cirúrgica, cardiologia, pneumologia, obstetrícia, ginecologia, dermatologia, neurologia, pediatria, psiquiatria, ortopedia, homeopatia e outras.

São realizados, também, procedimentos como: eletrocardiograma, testes ergométricos, teste de função pulmonar, biopsias, endoscopia digestiva, colonoscopia, pequenas cirurgias e exames de imagens (ultra-sonografia, tomografia computadorizada e outros). Embora o hospital não disponha de um serviço de emergência, um pronto-atendimento funciona diariamente no ambulatório de cirurgia atendendo àqueles clientes que necessitam de uma avaliação médica. Neste grupo incluem-se os clientes sem consulta agendada, transeuntes que apresentam mal-estar súbito ou pessoas não matriculadas que buscam atendimento médico.

0 quantitativo de funcionários lotados neste setor é de 5 enfermeiras ( 3 diaristas e 2 plantonistas), 44 auxiliares e 
técnicos de enfermagem (37 auxiliares e 7 técnicos de enfermagem) e 5 auxiliares administrativos. Uma enfermeira diarista ocupa o cargo de chefe do setor. As demais atuam em Programas do Ministério da Saúde (Tuberculose, Hanseníase, Pré-natal, Saúde da criança) e realizam a supervisão dos ambulatórios. 0 quadro de servidores de nível médio (auxiliares e técnicos de enfermagem) é integrado, majoritariamente, por pessoas do sexo feminino, sendo 41 mulheres e apenas 3 homens.

0 estudo foi encaminhado ao Comitê de Ética em Pesquisa do HUGG da UNIRIO para apreciação. Ele foi aprovado, e posteriormente procedemos à entrada em campo para coletar os dados. Foram respeitadas as recomendações da Resolução n. 196 / 96 do Conselho Nacional de Saúde, na ocasião da coleta, tendo-se informado aos participantes os objetivos do estudo, a livre participação e o emprego de pseudônimos para resguardar suas identidades.

Fizeram parte do estudo 15 auxiliares de enfermagem que aderiram ao mesmo. A escolha de funcionárias do sexo feminino deu-se em função da prevalência de mulheres entre os servidores lotados no setor e, também, por conta de férias e/ou licença médica dos demais trabalhadores na ocasião da coleta dos dados. As auxiliares de enfermagem foram abordadas em seu local de trabalho e questionadas quanto ao interesse em participar do estudo. Quando aderiram, foi solicitada a assinatura do Termo de Consentimento Livre e Esclarecido.

Os dados foram coletados no período de outubro de 2002 a janeiro de 2003. Uma entrevista foi realizada com o auxílio de um roteiro semi-estruturado e foi registrada através de gravação, com anuência das participantes. Durante o processo de coleta de dados, duas entrevistas foram descartadas em função de problemas técnicos com o equipamento de gravação. Os relatos foram analisados seguindo o processo de análise temática ${ }^{6}$ que possibilitou a categorização dos achados. Atribuiu-se um pseudônimo às participantes para garantir 0 anonimato. As depoentes apresentam o seguinte perfil: mulheres, com idades entre 35-55 anos, a maioria (12) com filhos, atuam na enfermagem há mais de quinze anos, possuem um vínculo empregatício (9) ou mais de um vínculo (6) e têm entre 10 e 15 anos de atuação profissional no ambulatório.

\section{ANÁLISE DOS RELATOS}

As entrevistas foram transcritas e analisadas, procedendo-se uma análise temática com os seguintes passos: pré-análise; exploração do material e tratamento dos resultados; interferência e interpretação $0^{6}$. As transcrições foram submetidas à leitura e releitura. Após a definição das unidades de registro no texto, identificamos e nomeamos os temas, ou unidades de significação, associados ao objeto de estudo. Em seguida, quantificamos os temas, bem como definimos e nomeamos as categorias. A partir da análise dos relatos emergiram as categorias: 3.1 . Estresse visto como distúrbio emocional; 3.2. Atividades profissionais contribuintes para o estresse; 3.3. Atividades diárias que contribuem para o estresse e 3.4. Os momentos de lazer, conforme apresentadas a seguir.

\subsection{Estresse visto como distúrbio emocional}

A análise das descrições evidenciou que 0 estresse é percebido pelas trabalhadoras como um distúrbio emocional que acarreta desequilíbrio da saúde mental ocasionando irritação, agitação, mau humor e incapacidade para o trabalho. Os recortes das descrições clarificam esta posição:

A facilidade de ficar irritada, descontrolada, mal humorada e etc (Ana).

É uma sobrecarga emocional que impede que o indivíduo desempenhe tarefas básicas do cotidiano, mantendo o perfeito equilibrio entre a razão e a emoção (Maria).

É irritação, agitação, descontrole emocional, agitação (Sonia).

Estado emocional relativo ao nervosismo, esgotamento físico e mental devido à prolongada exposição a diversos fatores como: desorganização, desrespeito profissional, hipocrisia e etc (Mariana).

Podemos perceber nesses recortes que as auxiliares de enfermagem relacionam a expressão "estresse" ao descontrole emocional que acarreta reações inesperadas, associando-o ao esgotamento físico e emocional. Nos dias atuais, é comum as pessoas referirem-se a esta denominação quando se deparam com alguém visivelmente irritado. Assim, expressões como "você está estressado", "está nervoso" ou "está irritado" são associadas ao esgotamento físico e mental que acomete muitas pessoas, especialmente aquelas que vivenciam situações geradoras de conflitos ou fortes emoções que ocasionem uma sobrecarga.

A expressão "estresse", difundida pelos diferentes meios de comunicação, tem sido empregada como causa ou explicação para inúmeros acontecimentos que afligem a vida humana moderna ${ }^{7}$. Esta expressão é geralmente associada à sensação de desconfor to e vista como algo que prejudica o desempenho global da pessoa ${ }^{3}$.

Neste sentido, foi constatado que, embora sejam conhecidos muitos fatores geradores de estresse dos trabalhadores, pouco se sabe sobre o tema em países em desenvolvimento, especialmente acerca dos aspectos psicossociais ${ }^{8}$. E sendo um fenômeno humano, sua abordagem deve ser vista com enfoque psíquico e social, não somente biológico, "considerando-se as especificidades individuais e os condicionantes do processo saúde-doença" $9: 70$.

Portanto, pode-se afirmar que o estresse trata de um esgotamento pessoal com interferência na vida do indivíduo que se manifesta através de sintomas físicos como: fadiga, dores de cabeça, insônia, dores no corpo, alterações intestinais e outros, além de sintomas psíquicos, mentais e emocionais como: ansiedade, nervosismo, medo e depressão, entre outros ${ }^{7}$.

Todavia, as situações estressantes afetam de maneira distinta o equilíbrio do profissional, considerando que cada pessoa "tem um grau de adaptação, dependendo da experiência prévia em manejar as demandas, do momento, do seu nível de adaptação, do tipo, número, intensidade e duração do agressor" 10: 548. 


\subsection{Atividades profissionais contribuintes para o estresse}

Em seus relatos, as auxiliares de enfermagem verbalizaram que as atividades profissionais realizadas em seu dia-a-dia contribuem para o estresse relacionando-o aos diferentes aspectos de seu ambiente de trabalho:

Sim, devido à falta de condições adequadas (espaç̧o físico, pessoal e material), assim como a convivência diária com a morte, a doença e o sofrimento de outrem (Maria).

Sim, por que trabalho em condições insatisfatórias, tem poucos funcionários, muitos doentes para atender, muitas solicitações ao mesmo tempo (Sonia).

Sim, porque trabalho com pessoas e é difícil atender e satisfazer as necessidades de cada um, já que os recursos são poucos e sempre falta alguma coisa, e geralmente as consultas são marcadas para longe (Ana).

O que concorre para o estresse é a constante situação e/ou situações a que ficamos expostas, e as diferenças de interesses das equipes (Joana).

Não minha profissão em si, mas as condições de trabalho atuais, sem material e sem recursos (Sofia).

Nas descrições dessas auxiliares podemos perceber que as condições de trabalho assumem importância significativa no desempenho de suas funções e interferem diretamente em seu fazer profissional, contribuindo para seu desgaste físico e emocional. Em geral, os trabalhadores de enfermagem estão expostos a uma elevada carga psíquica no desempenho de suas tarefas rotineiras, decorrentes do aspecto emocional pela convivência diária com a dor e o sofrimento alheios. Outro aspecto a ser considerado são os recursos disponíveis, tais como pessoal e material, para a realização das atividades que, na rede pública, são escassos contribuindo para a elevação da carga psíquica laboral.

Diante das condições psicológicas do trabalho e suas conseqüências sobre a saúde do trabalhador, a organização do trabalho é um fator potencialmente desestabilizador da saúde mental dos trabalhadores ${ }^{4}$. Condições de trabalho são "[...] as pressões físicas, mecânicas, químicas e biológicas do posto do trabalho" ${ }^{\text {: } 125}$. Essas pressões agem no corpo dos trabalhadores e podem provocar doenças somáticas. Assim, "a relação do homem com a organização do trabalho é a origem da carga psíquica do trabalho"11:30 ou seja, quanto mais harmoniosa for a relação do homem com o seu trabalho melhor será sua saúde psíquica.

As condições e a organização do trabalho apresentam características que podem configurar elevada carga mental do trabalho. Assim, as precárias condições de trabalho a que muitos profissionais de enfermagem ficam expostos, especialmente em instituições públicas de assistência à saúde, são um dos fatores geradores de desgaste físico e mental que prejudicam o desempenho das atividades laborais desses trabalhadores.

Em estudo que analisou os problemas ocupacionais decorrentes do trabalho de enfermagem no Brasil, afirma-se que, em grande parte da nação, a Enfermagem brasileira enfrenta problemas relacionados à falta de soberania, sendo submissa ao seu empregador ${ }^{12}$. Esses aspectos associados às precárias condições de trabalho ocasionam o sofrimento emocional do trabalhador que:

Executa sua atividade profissional em hospitais, particularmente os pertencentes a rede pública. [...] há falta de recursos humanos e materiais [...]. Observase a utilização de tecnologias sofisticadas ao lado de assistência precária aos clientes, onde às vezes não se encontram roupas para cobri-los, medicamentos para Ihes serem ministrados ${ }^{12: 333}$.

A assistência de enfermagem nas instituições públicas, em geral, tem sido penalizada com a deficiência dos recursos humanos e materiais, o que interfere diretamente na qualidade da assistência prestada à população, gerando insatisfação nos profissionais que se sentem impotentes e frustrados com a situação. Este quadro tem sido analisado por alguns autores ${ }^{13,14}$, que descrevem a realidade dos profissionais de enfermagem nos hospitais públicos retratando seu sofrimento relacionado às condições cotidianas de trabalho.

A deterioração das condições de trabalho do profissional de enfermagem tem levado a categoria a uma situação tal que a crescente evasão e a alta rotatividade têm promovido aumento do "desgaste físico e mental dos trabalhadores remanescentes, na medida em que as atividades precisam ser redistribuídas entre os que permanecem sem possibilidades de manutenção da qualidade de assistência prevista"13: 69 .

Um estudo que avaliou o estresse nas atividades ocupacionais dos enfermeiros constatou que para os enfermeiros assistenciais os elementos estressores podem estar relacionados aos recursos inadequados, ao atendimento ao paciente, às relações interpessoais e à carga emocional ${ }^{3}$. Confirmando àqueles resultados, nos relatos das trabalhadoras fica evidente a presença dos mesmos elementos, ao mencionarem os aspectos que ocasionam o desgaste ocupacional.

\subsection{As atividades diárias contribuem para o estresse}

As atividades da vida cotidiana realizadas pelas auxiliares de enfermagem, enquanto trabalhadoras e pessoas inseridas num contexto social, contribuem para o estresse conforme explicitam os recortes que se seguem:

Sim, devido à falta de segurança, política salarial, trânsito caótico (Maria).

Sim, porque estou geralmente com pressa (Ana).

Sim porque faço várias coisas ao mesmo tempo. Trabalho e cuido da organização da casa, filhos, marido ... (Sonia).

A rotina em si, associada aos fatores sócio-econômicos $e$ às situações ambientais, contribui não só para o estresse, como também para hipertensão, hiperglicemia e etc., até mesmo para a obesidade (Joana).

Sim. Minha vida pessoal, o ambiente familiar, o convivio com o esposo ... enfim, tudo (Sofia).

Conforme as descrições, as atividades laborais associadas às condições de vida das trabalhadoras contribuem para que 
se sintam "estressadas", ou seja cansadas, desgastadas. No relato de Sonia fica evidente a relação de gênero quando se interpõem os papéis da mulher, da trabalhadora e da mãe vivenciados pela profissional. Considerando que a Enfermagem é uma profissão que, ainda nos dias atuais, é predominantemente feminina e que, em muitas situações, as trabalhadoras necessitam ter mais de um vínculo empregatício, pode-se compreender a dimensão da fala desta profissional ao afirmar que faz "várias coisas ao mesmo tempo". Este pensamento é corroborado nos relatos de Sofia e Joana, que alertam, também, para 0 aspecto financeiro e associam as condições de vida às manifestações de patologias no corpo físico, tais como a hipertensão, hiperglicemia e obesidade.

Estes aspectos assinalados nos discursos das profissionais perpassam a realidade de muitas trabalhadoras que realizam dupla ou tripla jornada de trabalho, ao se somarem as atividades profissionais àquelas realizadas no âmbito doméstico. Esta sobrecarga de trabalho leva muitas profissionais à exaustão e a outros comprometimentos físicos que ocasionam 0 afastamento da atividade laboral. Por outro lado, nos dias atuais, muitas mulheres estão assumindo sozinhas a responsabilidade econômica de seus lares e, por este motivo, necessitam trabalhar mais, ocasionando o desgaste físico e mental.

Confirmando esta análise, um estudo sobre mãestrabalhadoras de enfermagem de uma instituição pública constatou que a sobrecarga de trabalho contribui para 0 cansaço e desgaste dessas mulheres, que freqüentemente negligenciam o autocuidado, em função da "falta de tempo", ficando expostas aos agravos à saúde ${ }^{15}$.

Em relação à presença da população feminina no mercado de trabalho brasileiro, os recenseamentos do Instituto Brasileiro de Geografia e Estatística ${ }^{16}$ indicam que cada vez é maior o número de mulheres incluídas entre as pessoas economicamente ativas. A Pesquisa Nacional por Amostra de Domicilios, de 2004, indicou que a taxa de mulheres ocupadas era de $43,1 \%$, sendo $70,6 \%$ com idades de $25-49$ anos; $64,2 \%$ de 18-24 anos e 52,2\% de 50-59 anos. A participação feminina no mercado de trabalho das regiões metropolitanas do nordeste e sudeste do país aumentou, principalmente nas cidades de Salvador, Fortaleza, Recife, Rio de Janeiro e Belo Horizonte ${ }^{17}$. Estes dados estão em consonância com o grupo investigado, composto por profissionais do sexo feminino, com idades entre 35 e 55 anos e, em muitas situações, responsáveis por suas famílias.

A Enfermagem é uma profissão integrada, em sua maioria, por pessoas do sexo feminino. É comum as profissionais terem mais de um vínculo empregatício, em função dos baixos salários. Estes fatores associados aos aspectos culturais que condicionam a mulher a desempenhar as atividades domésticas mesmo que exerça um trabalho remunerado leva ao acúmulo de funções que a sobrecarregam. A dupla (ou tripla) jornada das trabalhadoras de enfermagem apresenta-se como um fator desestabilizador de seu equilibrio mental, ocasiona o sofrimento psíquico e gera desmotivação e insatisfação no trabalho ${ }^{18}$.

No ambulatório das instituições públicas é comum encontrarmos pessoas mais maduras, experientes, que foram remanejadas para este setor em função de patologias que dificultavam o seu desempenho profissional. Com isto, esses locais acabam sendo superlotados de pessoas portadoras de limitações para 0 trabalho ${ }^{19} .0$ desgaste dos trabalhadores de enfermagem envolve os processos de inadaptação ao trabalho, as indisposições passageiras e 0 envelhecimento precoce que "podem caracterizar-se em doenças instaladas e passíveis de diagnóstico clínico, como é o caso das doenças crônicas que são responsáveis pela maior parte dos afastamentos do trabalho" 19:457.

\subsection{Os momentos de lazer}

As auxiliares de enfermagem verbalizaram o que fazem em seus momentos de folga ou de descanso do trabalho remunerado, entendidos como momentos de lazer. Elas descrevem suas atividades assim:

Leio, vejo filmes, faço caminhada ao ar livre (Maria).

Ultimamente, não tenho feito nada (Ana).

Faço natação, vejo TV, durmo, passeio (Sonia).

Leio, vou ao shopping, quando possivel assisto TV, ouço música, cuido das plantas, caminho e, por último, procuro dormir (Joana).

Vou à Igreja. A vida religiosa me completa e me tranqüiliza (Sofia).

Qualquer coisa que seja agradável no momento, como leitura, assistir televisão, cinema, nadar, tomar sol, brincar com meus filhos ... (Luiza).

Conforme estas descrições, os momentos de folga são destinados ao relaxamento, à distração e execução de tarefas que não estejam associadas às suas atividades laborais na Enfermagem. Enquanto para algumas o momento de lazer é uma ocasião de sair da rotina e realizar coisas como "brincar com os filhos" e "assistir televisão", o relato de Ana é contundente ao afirmar que ultimamente não tem feito nada. Ela não associa "momentos de lazer" às atividades que realiza fora do ambiente de trabalho. É interessante observarmos que é comum entre os profissionais da área de saúde, e especialmente na Enfermagem, a existência de mais de um vínculo empregatício, muitas vezes por razões financeiras, 0 que faz com que esses trabalhadores disponham de pouco tempo para o lazer, o que provavelmente poderia justificar o relato de Ana. Neste sentido, o lazer é:

A válvula de escape do trabalho, um tempo para esquecer dos problemas responsáveis pelo estresse e para se reequilibrar dos "transtornos" do cotidiano. É compreendido, pois, como essencial e parte integrante da vida, na busca de liberação e prazer, um retorno à infância, sendo a disponibilidade de tempo e a atitude seus pressupostos básicos ${ }^{20: 79}$.

As atividades de enfermagem no seu cotidiano podem ocasionar o desgaste físico e mental dos trabalhadores. Neste sentido, observa-se que os profissionais acabam sendo absorvidos pelas rotinas de serviço, o que, aliado à sobrecarga de trabalho, pode provocar a exaustão do trabalhador. Todavia, deve-se considerar que o organismo do trabalhador não pode ser visto como uma máquina. Em sua condição humana, ele 
constantemente é estimulado pelo ambiente e sofre a sua influência. 0 trabalhador "possui uma história pessoal que se concretiza por uma certa qualidade de suas aspirações, de seus desejos, de suas motivações, de suas necessidades psicológicas"11:24.

Portanto, é necessário que o trabalhador sinta-se estimulado, se identifique com o tipo de tarefa que está realizando, para que estabeleça uma relação de prazer com o trabalho. Do contrário, o trabalho tornar-se-á uma fonte de tensão e desprazer. Entretanto, o lazer é importante para a saúde mental das pessoas, sendo essencial que se promovam situações para oportunizar momentos de descontração e relaxamento no cotidiano das organizações e no dia-a-dia dos trabalhadores. Nesta perspectiva, muitas empresas preocupadas com a saúde física e mental de seus trabalhadores têm adotado estratégias para contornar a exaustão, seja estimulando a prática de exercícios físicos e esportes ao longo da jornada de trabalho, ou pela introdução de técnicas de relaxamento para seus trabalhadores, conscientes de que eles produzem mais e melhor se estiverem em perfeita harmonia com o corpo e a mente. Neste sentido, se um trabalho:

Permite a diminuição da carga psíquica, ele é equilibrante. Se ele se opõe a essa diminuição, ele é fatigante. [...] A energia psíquica se acumula, tornandose fonte de tensão e desprazer, a carga psíquica cresce até que aparecem a fadiga, a astenia e, a partir daí, a patologia: é o trabalho fatigante.[... $]^{11: 25}$.

Nesta concepção, o trabalho acumula uma carga psíquica que se manifesta no corpo do trabalhador através de sintomas como apatia, astenia e fadiga. Portanto, torna-se relevante que 0 trabalhador cultive hábitos que contribuam para 0 restabelecimento de seu equilíbrio físico e mental, como os momentos de lazer e descontração.

Um estudo que analisou a relação entre o trabalho, a saúde e as condições de vida de trabalhadoras de enfermagem constatou que as profissionais são expostas a ambientes de trabalho insalubres, no sentido material e subjetivo, e são submetidas às condições de trabalho precarizadas. Ele ainda refere que o grupo investigado dispõe de tempo insuficiente para o descanso e lazer, conformando-se com o fato. Esses fatores associados às condições de vida das trabalhadoras potencializam as possibilidades de adoecimento ${ }^{21}$.

\section{CONSIDERAÇÕES FINAIS}

Este estudo permitiu perceber que, embora as auxiliares de enfermagem definam o estresse como um distúrbio e atuem em condições desfavoráveis, nem todas percebem a influência destes fatores no seu equilíbrio emocional. Assim, apesar de atualmente os trabalhadores terem mais acesso a informações relativas aos aspectos ergonômicos de sua saúde, poucos são àqueles que reivindicam melhorias nas condições de trabalho, ficando subjugados aos seus empregadores. Em geral, o ritmo de trabalho dos profissionais de enfermagem é intenso, cansativo, pela realização de tarefas superpostas e repetitivas, ocasionando o esgotamento físico e mental dos mesmos. Em muitas situações, esses profissionais:
[...] Nem sabem identificar seus problemas, queixamse de dores nas costas, dores na coluna, falta de ânimo ou prazer em ir trabalhar, surgem os conflitos no ambiente laboral e familiar, aumentando o absenteísmo e a rotatividade no emprego $0^{2: 557}$.

Os participantes do estudo são do sexo feminino, e seus relatos, portanto, devem ser analisados à luz das questões que envolvem o gênero, observando-se a sobrecarga decorrente da dupla (ou tripla) jornada, a multiplicidade de papéis, os conflitos da mulher-mãe trabalhadora e outras situações que interferem diretamente em sua saúde física e mental. Vale acrescentar que, ultimamente 0 absenteísmo tem aumentado significativamente entre os auxiliares e técnicos de enfermagem no ambulatório do HUGG relacionado a diversos fatores, dentre eles a incapacidade física e/ou agravos à saúde dos mesmos.

Neste sentido, um estudo que avaliou o absenteísmo e a satisfação no trabalho de enfermeiras em Hong Kong constatou que existe uma inter-relação entre o absenteísmo e o ambiente de trabalho ${ }^{22}$. 0 mal-estar psicológico pode ser um antecedente da satisfação no trabalho, e a satisfação no trabalho pode ser um antecedente do absenteísmo. Este estudo ainda recomenda que o ambiente de trabalho deveria ser melhorado para se elevar a satisfação no trabalho, reduzir a angústia e, conseqüentemente, reduzir o absenteísmo ${ }^{22}$. Temos consciência de que a precariedade de recursos no HUGG é um fator que contribui de maneira significativa para o sofrimento psíquico dos profissionais de enfermagem, favorecendo a ocorrência de distúrbios que se manifestam na saúde física e mental dos trabalhadores.

Por outro lado, o trabalho pode ser uma fonte de prazer e um mediador da saúde. Assim, "muitos sujeitos só conseguem salvar seu equilíbrio e obter satisfações afetivas graças ao trabalho. De maneira que trabalho e sublimação aparecem como operadores fundamentais da saúde mental"23: 159. Sabemos os benefícios que o trabalho representa para a saúde mental do trabalhador. Todavia, especialmente na área de saúde, há de se empreenderem esforços para a manutenção da saúde dos profissionais no desempenho da atividade laboral. Entretanto, é interessante salientar que, embora a profissão exija uma boa saúde física e mental de seus profissionais, raramente esses trabalhadores:

[...] Recebem a proteção social adequada para o seu desempenho (...) apesar de exercerem atividades estafantes, muitas vezes em locais inadequados, não recebem a atenção e proteção necessárias para evitar os acidentes e as doenças decorrentes das atividades ${ }^{7: 260}$.

No cenário onde o estudo ocorreu esta realidade pode ser observada. É freqüente os servidores se queixarem de indisposições físicas, tentarem buscar auxílio imediato ou acompanhamento posterior e nem sempre obtêm êxito em suas tentativas, pela ineficiência (ou deestruturação) do serviço de saúde do trabalhador. Por este motivo, muitas trabalhadoras negligenciam o autocuidado, o que acarreta agravos em sua saúde física, ou buscam atendimento fora do seu local de trabalho em planos de assistência privada ${ }^{15}$.

As más condições de trabalho estão presentes no dia-a-dia de muitos profissionais de enfermagem que atuam em 
instituições públicas de assistência à saúde, no município do Rio de Janeiro. As deficiências de recursos humanos e materiais foram referidas como fatores que dificultam a prestação de assistência à clientela, acarretando desgaste e sofrimento da trabalhadora de enfermagem. 0 corpo dos trabalhadores recebe 0 impacto das condições de trabalho, cuja organização age sobre o funcionamento mental das pessoas ${ }^{11}$. Assim, as más condições de trabalho trazem prejuízos para o corpo dos trabalhadores e, também, para sua saúde psíquica.

Portanto, torna-se relevante valorizar a saúde mental dos trabalhadores, especialmente os profissionais de enfermagem, que necessitam estar bem física e mentalmente para interagirem com e auxiliarem a clientela. A implementação de ações que favoreçam a integração dos profissionais de enfermagem; a melhoria das condições de trabalho, observando-se os aspectos ergonômicos e a promoção da saúde do trabalhador; a atuação do serviço de saúde do trabalhador na prevenção de doenças ocupacionais e agravos à saúde são algumas medidas que deveriam ser repensadas (e instituídas) pelos coordenadores de enfermagem para promover o bemestar físico e mental dos profissionais da área, considerando que os profissionais de enfermagem, como pessoas que cuidam

\section{Referências}

1. Lipp MEN. Stress: conceitos básicos. In: Lipp MEN, organizadora. Pesquisas sobre stress no Brasil: saúde, ocupações e grupos de risco. Campinas (SP): Papirus; 1996.

2. Vianey EL, Brasileiro ME. Saúde do trabalhador: condições de trabalho do pessoal de enfermagem em hospital psiquiátrico. Rev Bras Enferm 2003 set; 56(5): 555-57.

3. Stacciarini JMR, Tróccoli BT. 0 estresse na atividade ocupacional do enfermeiro. Rev Latino-am Enfermagem 2001 mar; 9(2): 17-25.

4. Dejours C, Abdoucheli E. Itinerário teórico em psicopatologia do trabalho. In: Dejours C, Abdoucheli E, Jayet C. Psicodinâmica do trabalho: contribuições da Escola Dejouriana à análise da relação prazer, sofrimento e trabalho. São Paulo(SP): Atlas; 1994.

5. Lipp M, Malagris L. Mitos e verdades sobre o stress. São Paulo (SP): Contexto; 1996.

6. Bardin L. Análise de conteúdo. Lisboa (PT): Ed 70; 1977.

7. Murofuse NT, Abranches SS, Napoleão AA. Reflexões sobre estresse e burnout e a relação com a enfermagem. Rev Latino-am Enfermagem 2005 mar; 13(2): 255-61.

8. Areias MEQ. Saúde mental, estresse e trabalho dos servidores de uma universidade. [tese de doutorado] São Paulo (SP): Faculdade de Ciências Médicas/ UEC; 1999.

9. Costa JRA, Lima JV, Almeida PC. Stress no trabalho do enfermeiro. Rev Esc Enferm USP 2003 set; 37(3): 63-71.

10. Caregnato RCA, Lautert L. 0 estresse da equipe multiprofissional na sala de cirurgia. Rev Bras Enferm 2005 set; 58(5): 545-50. de outras pessoas, necessitam ser percebidos como seres dotados de sentimentos e emoções.

É preciso que se perceba que a saúde no trabalho é um direito do trabalhador ${ }^{24}$. Assim sendo, estudiosos ${ }^{24}$ da temática enfatizam ser relevante a adoção de medidas que promovam o bem-estar dos trabalhadores e previnam o aparecimento de doenças. Também, é necessário que se criem estratégias para o tratamento e reabilitação de profissionais com doenças psíquicas relacionadas com o trabalho para melhorar sua auto-estima e valorização.

Nesse sentido, convém ressaltar que as condições e organização do trabalho na Enfermagem podem interferir na elevação da carga psíquica desses trabalhadores e em sua saúde mental. Assim, são relevantes as medidas institucionais que objetivem elevar o bem-estar dessas pessoas no ambiente laboral, bem como que o próprio trabalhador seja estimulado a cultivar hábitos saudáveis que contribuam para sua saúde, como a prática de exercícios físicos ou demais atividades que proporcionem seu relaxamento, como também a adoção de uma alimentação equilibrada evitando-se os excessos. Agindo deste modo o trabalhador de enfermagem, além de preservar sua integridade física e mental, estaria contribuindo para harmonizar corpo e mente, prevenindo-se do estresse ocupacional.

11. Dejours C. A carga psíquica do trabalho. In: Dejours C, Abdoucheli E, layet C. Psicodinâmica do trabalho: das contribuições da Escola Dejouriana à análise da relação prazer, sofrimento e trabalho. São Paulo (SP): Atlas; 1994.

12. Robazzi MLCC, Marziale MHP. Alguns problemas ocupacionais decorrentes do trabalho de enfermagem no Brasil. Rev Bras Enferm 1999 jul; 52 (3): 331-38.

13. Lunardi Filho WD. Prazer e sofrimento no trabalho: contribuições à organização do processo de trabalho da enfermagem. [dissertação de mestrado]. Rio Grande do Sul (RS): Faculdade de Ciências Econômicas/URGS; 1995.

14. Silva VEF, Kurcgant P, Queiroz VM. 0 desgaste do trabalhador de enfermagem: relação trabalho de enfermagem e saúde do trabalhador. Rev Bras Enferm 1998 out; 51(4): 603-14.

15. Spindola T. Trabalho feminino: muitos papéis... uma só mulher: ambivalências do cotidiano. [tese de doutorado]. Rio de Janeiro (RJ): Escola de Enfermagem Anna Nery/ UFRJ; 2002.

16. Instituto Brasileiro de Geografia e Estatística-IBGE. Perfil de mulheres responsáveis pelos domicilios no Brasil, 2000. Rio de Janeiro: (RJ); 2002. 17. Instituto Brasileiro de Geografia e Estatística- IBGE. Síntese de indicadores sociais. Pesquisa Nacional por Amostra de Domicílios 2005. Rio de Janeiro: (RJ); 2006.

18. Costa MS, Silva MJ, Alves MSD, Oriá MOB. Estilo de vida e saúde mental: estudo de caso com enfermeiros. Rev Enferm UERJ 2005 mai; 13(2): 199-03.

19. Rocha AM, Felli VEA. A saúde do trabalhador de enfermagem sob a ótica da gerência. Rev Bras Enferm 2004 jul; 57(4): 453-58.

20. Camargo RAA, Bueno SMV. Lazer na promoção da saúde mental. Esc Anna Nery Rev Enferm 2004 abr; 8(1): 71-80. 
21. Elias MA, Navarro VL. A relação entre o trabalho, a saúde e as condições de vida: negatividade e positividade no trabalho das profissionais de enfermagem de um hospital escola. Rev Latino-am Enfermagem 2006 jul; 14(4): 517-25.

22. Siu OL. Predictors of job satisfaction and absenteeism in two samples of Hong Kong nurses. J Adv Nurs 2002 0ct; 40(2): 218-29.

23. Dejours C. Uma nova visão do sofrimento humano nas organizações. In: Chanlat JF. 0 indivíduo na organização: dimensões esquecidas. $3^{\text {a }}$ ed. São Paulo (SP): Atlas; 1996.

24. Gomes GC, Lunardi Filho WD, Erdmann AL. 0 sofrimento psíquico em trabalhadores de UTI interferindo no seu modo de viver a enfermagem. Rev Enferm UERJ 2006 jan; 14(1): 93-09.

\section{Sobre as Autoras}

\section{Thelma Spindola}

Doutora em Enfermagem. Professora Adjunta da Faculdade de Enfermagem da Universidade do Estado do Rio de Janeiro. Enfermeira do HUGG / UNIRIO.

\section{Elizabeth Rose da Costa Martins}

Doutoranda em Enfermagem da EEAN/UFRJ. Professora Assistente da Faculdade de Enfermagem da Universidade do Estado do Rio de Janeiro. 